\title{
Заболеваемость раком легкого в Республике Башкортостан: ретроспективные данные
}

1 - ГОУ ВПО " Башкирский государственный медицинский университет Росздрава", кафедра внутренних болезней: 450000, Респубблика Башкортостан, Уфа, ул. Ленина, 3;

2 - ГОУ ВПО " Башкирский государственный медицинский университет Росздрава", кафедра хирургии и онкологии: 450000, Республика Башкортостан, Уфа, ул. Ленина, 3

\section{Kh.Kh.Gantseva, I.R.Rakhmatullina, D.M.Gabitova \\ Lung cancer morbidity in Bashkortostan Republic: a retrospective analysis}

\begin{abstract}
Summary
A retrospective analysis of lung cancer morbidity in adult population of Bashkortostan Republic in 1993-2002 has been performed. As a result, we obtained data on morbidity and its tendency, relationship between level of morbidity and its dynamics in different periods in dependence on the people's age. Intensive and standard values of lung cancer morbidity were estimated.

Key words: lung cancer, morbidity.
\end{abstract}

\section{Резюме}

Проведен ретроспективный анализ заболеваемости раком легкого взрослого населения Республики Башкортостан за период с 1993 по 2002 г. В результате проведенного исследования были получены показатели заболеваемости, тенденции, закономерности уровня и динамики заболеваемости раком легкого в разные годы в зависимости от возраста пациентов.

Ключевые слова: рак легкого, заболеваемость.

Заболеваемость населения раком легкого (РЛ) за последние 50 лет резко возросла во многих странах мира. В настоящее время в большинстве развитых стран РЛ является наиболее распространенной формой опухоли у мужчин и остается одной из важнейших медицинских и социально-экономических проблем. Ежегодно в мире регистрируется 1,3 млн новых случаев РЛ, из них 60 \% приходится на развитые страны [1, 2]. Курение является наиболее важным фактором РЛ. Риск развития этого заболевания среди курящих, в среднем, в 10 раз выше, чем у некурящих [3, 4].

Доля РЛ, связанного с профессиональными факторами колеблется в пределах от 4 до 40 \%, в зависимости от места и времени проводимого исследования, а так же от концентрации в зоне эпидемиологического исследования в определенный период времени того или иного канцерогенного фактора. Необходимо отметить, что курение при наличии профессиональных факторов, существенно повышает риск возникновения РЛ [5].

РЛ в большей степени, чем другие формы злокачественных опухолей, связан с загрязнением атмосферного воздуха канцерогенными веществами. Эти вещества обнаруживаются не только на территории промышленных предприятий, выбрасывающих их, в промышленных центрах, вдоль автомобильных магистралей, но и далеко за их пределами. Население, проживающее в городах и территориально-промышленных комплексах с высоким индустриальным развитием, преимущественно тяжелой, химической, нефтехимической и нефтеперерабатывающей промышленности, чаще поражается онкологическими заболеваниями, в т. ч. РЛ, чем в городах, специализирующихся на легкой и пищевой промышленности $[4,5]$.

Целью исследования был анализ половозрастных показателей заболеваемости РЛ населения Республики Башкортостан (РБ) за многолетний период.

\section{Материалы и методы}

Проведен ретроспективный анализ заболеваемости РЛ взрослого населения РБ за период с 1993 по 2002 г.

Сбор информации осуществлялся путем выкопировки данных из отчетной формы № 7 "Сведения о заболеваниях злокачественными новообразованиями" и компьютерной базы данных Республиканского клинического онкологического диспансера МЗ РБ. При сборе первичной информации использовали свод статистических и отчетных данных, извещения на больных со впервые установленным диагнозом злокачественного новообразования (форма № 090/у); форму № 281; журналы учета, регистрации выявленных злокачественных новообразований, а также отчет о больных злокачественными новообразованиями (форма № 35). Исследование проводилось сплошным методом. Сведения о численности и половозрастном составе населения РБ были получены в Госкомстате РБ. В результате проведенного исследования были получены показатели заболеваемости, тенденции, закономерности уровня и динамики заболеваемости 
РЛ в разные годы в зависимости от возраста. Исчислялись интенсивные ("грубые") и стандартизованные показатели онкологической заболеваемости.

\section{Результаты и обсуждение}

Динамика "грубых" и стандартизованных показателей заболеваемости РЛ среди групп взрослого населения РБ за 1993-2002 гг. представлена в табл. 1-3. За период с 1993 по 2002 г. усредненный "грубый" по- казатель заболеваемости новообразованиями трахеи, бронхов, легкого среди мужского населения РБ старше 15 лет составил 89,2 на 100 тыс. населения, стандартизованный - 76,5 на 100 тыс. населения. В популяции взрослого населения РБ эти показатели составляли 48,0 на 100 тыс. и 34,9 на 100 тыс. населения соответственно. Соотношение усредненного "грубого" показателя заболеваемости мужского населения РБ старше 15 лет и всего мужского населения составило 1,3. Наибольший усредненный "грубый"

Таблица 1

Тенденции первичной заболеваемости РЛ в возрастных группах взрослого мужского населения РБ за 1993-2002 г2. в "грубых" (I) и стандартизованных (II) показателях

\begin{tabular}{|c|c|c|c|c|c|c|c|c|c|c|c|c|c|c|c|c|c|c|c|c|c|c|}
\hline \multirow[t]{2}{*}{$\begin{array}{l}\text { Возрастные } \\
\text { группы, лет }\end{array}$} & \multicolumn{2}{|c|}{1993} & \multicolumn{2}{|c|}{1994} & \multicolumn{2}{|c|}{1995} & \multicolumn{2}{|c|}{1996} & \multicolumn{2}{|c|}{1997} & \multicolumn{2}{|c|}{1998} & \multicolumn{2}{|c|}{1999} & \multicolumn{2}{|c|}{2000} & \multicolumn{2}{|c|}{2001} & \multicolumn{2}{|c|}{2002} & \multicolumn{2}{|c|}{$\begin{array}{l}\text { Усред- } \\
\text { ненные }\end{array}$} \\
\hline & I & II & I & II & I & II & I & II & I & II & I & II & I & II & I & II & I & II & I & II & I & II \\
\hline $15-19$ & 1,1 & 0,1 & 0,6 & 0,1 & 0 & 0 & 0 & 0 & 0 & 0 & 0 & 0 & 0,5 & 0 & 0,5 & 0 & 0 & 0 & 0 & 0 & 0,27 & 0,02 \\
\hline $20-24$ & 0 & 0 & 0,7 & 0,1 & 0 & 0 & 0 & 0 & 0 & 0 & 1,4 & 0,1 & 0 & 0 & 0,7 & 0,1 & 0 & 0 & 0 & 0 & 0,28 & 0,03 \\
\hline $25-29$ & 0 & 0 & 0,7 & 0,1 & 1,5 & 0,1 & 1,5 & 0,1 & 1,5 & 0,1 & 0 & 0 & 0,7 & 0,1 & 0,7 & 0,1 & 0 & 0 & 0,7 & 0,1 & 0,73 & 0,07 \\
\hline $30-34$ & 4,4 & 0,3 & 1,1 & 0,1 & 2,5 & 0,1 & 3,7 & 0,2 & 1,3 & 0,1 & 0 & 0 & 2,2 & 0,1 & 3 & 0,2 & 3,8 & 0,2 & 3 & 0,2 & 2,5 & 0,15 \\
\hline $35-39$ & 8 & 0,5 & 8,6 & 0,5 & 8,8 & 0,5 & 4,4 & 0,3 & 5,4 & 0,3 & 8,7 & 0,5 & 7,8 & 0,5 & 5,9 & 0,4 & 3,7 & 0,2 & 6,9 & 0,4 & 6,82 & 0,41 \\
\hline $40-44$ & 25,7 & 1,5 & 33,3 & 2 & 24,6 & 1,5 & 24 & 1,4 & 27,2 & 1,6 & 16,7 & 1 & 14,9 & 0,9 & 23,1 & 0,4 & 18 & 1,1 & 18 & 1,1 & 22,6 & 1,25 \\
\hline $45-49$ & 51,2 & 3,1 & 89,7 & 5,4 & 61,5 & 3,7 & 65,1 & 3,9 & 69,8 & 4,2 & 58,7 & 3,5 & 63,6 & 3,8 & 56,8 & 3,4 & 62,6 & 3,8 & 47,3 & 2,8 & 62,6 & 3,76 \\
\hline $50-54$ & 145 & 7,2 & 113 & 5,7 & 130 & 6,5 & 114 & 5,7 & 149 & 7,4 & 118 & 5,9 & 118 & 5,9 & 111 & 5,6 & 127 & 6,4 & 134 & 6,7 & 126 & 6,3 \\
\hline $55-59$ & 244 & 9,7 & 126 & 5 & 231 & 9,2 & 203 & 8,1 & 207 & 8,3 & 203 & 8,1 & 213 & 8,5 & 233 & 9,3 & 193 & 7,7 & 201 & 8 & 205 & 8,19 \\
\hline $60-64$ & 321 & 12,8 & 301 & 12 & 321 & 12,8 & 343 & 13,7 & 307 & 12,3 & 309 & 12,3 & 299 & 12 & 303 & 12,1 & 294 & 11,8 & 258 & 10,3 & 306 & 12,2 \\
\hline $65-69$ & 475 & 14,3 & 541 & 16,2 & 425 & 12,7 & 388 & 11,7 & 411 & 12,3 & 392 & 11,8 & 355 & 10,7 & 378 & 11,3 & 373 & 11,1 & 365 & 10,9 & 410 & 12,3 \\
\hline $70-74$ & 442 & 8,8 & 478 & 9,6 & 359 & 7,2 & 441 & 8,8 & 484 & 9,7 & 462 & 9,2 & 408 & 8,2 & 398 & 8 & 450 & 9 & 408 & 8,2 & 433 & 8,67 \\
\hline $75-79$ & 485 & 4,9 & 424 & 4,2 & 457 & 4,6 & 259 & 2,6 & 489 & 4,9 & 398 & 4 & 361 & 3,6 & 446 & 4,5 & 437 & 4,4 & 511 & 5,1 & 427 & 4,28 \\
\hline $80-84$ & 113 & 0,6 & 141 & 0,7 & 306 & 1,5 & 234 & 1,2 & 192 & 1 & 269 & 1,3 & 279 & 1,4 & 167 & 0,8 & 238 & 1,2 & 345 & 1,7 & 228 & 1,14 \\
\hline$\geq 85$ & 96 & 0,5 & 116 & 0,6 & 138 & 0,7 & 207 & 1 & 217 & 1,1 & 113 & 0,6 & 140 & 0,7 & 170 & 0,8 & 189 & 0,9 & 205 & 1 & 159 & 0,79 \\
\hline$\geq 15$ & 92 & 82,4 & 92,2 & 79,7 & 102 & 78,5 & 97,8 & 75,3 & 90,6 & 81,1 & 85,5 & 74,9 & 81,7 & 72,2 & 83,6 & 74,3 & 84,4 & 74,1 & 81,7 & 72,6 & 89,2 & 76,5 \\
\hline $\begin{array}{l}\text { Bce } \\
\text { население }\end{array}$ & 68,8 & 64,3 & 69,1 & 62,2 & 67,7 & 61,2 & 64,8 & 58,7 & 69,6 & 63,3 & 66,3 & 58,4 & 64,1 & 56,3 & 66,3 & 57,9 & 67,8 & 57,8 & 65,6 & 56,6 & 67 & 59,7 \\
\hline
\end{tabular}

Таблица 2

Тенденции первичной заболеваемости РЛ в возрастных группах взрослого женского населения РБ за 1993-2002 г2. в "грубых" (I) и стандартизованных показателях (II)

\begin{tabular}{|c|c|c|c|c|c|c|c|c|c|c|c|c|c|c|c|c|c|c|c|c|c|c|}
\hline \multirow[t]{2}{*}{$\begin{array}{l}\text { Возрастные } \\
\text { группы, лет }\end{array}$} & \multicolumn{2}{|c|}{1993} & \multicolumn{2}{|c|}{1994} & \multicolumn{2}{|c|}{1995} & \multicolumn{2}{|c|}{1996} & \multicolumn{2}{|c|}{1997} & \multicolumn{2}{|c|}{1998} & \multicolumn{2}{|c|}{1999} & \multicolumn{2}{|c|}{2000} & \multicolumn{2}{|c|}{2001} & \multicolumn{2}{|c|}{2002} & \multicolumn{2}{|c|}{$\begin{array}{l}\text { Усред- } \\
\text { ненные }\end{array}$} \\
\hline & I & II & I & II & I & II & I & II & I & II & I & II & I & II & I & II & I & II & I & II & I & II \\
\hline $15-19$ & 0 & 0 & 0 & 0 & 0,5 & 0 & 0,5 & 0 & 0 & 0 & 0 & 0 & 0 & 0 & 0 & 0 & 0 & 0 & 0 & 0 & 0,1 & 0 \\
\hline 20-24 & 0 & 0 & 0,8 & 0,1 & 0,7 & 0,1 & 0 & 0 & 0 & 0 & 0 & 0 & 0 & 0 & 0 & 0 & 0,7 & 0,1 & 0 & 0 & 0,22 & 0,03 \\
\hline $25-29$ & 0,7 & 0,1 & 0,7 & 0,1 & 0 & 0 & 2,3 & 0,2 & 0 & 0 & 0 & 0 & 2,3 & 0,2 & 0 & 0 & 0,7 & 0,1 & 0 & 0 & 0,67 & 0,07 \\
\hline $30-34$ & 0,6 & 0 & 2,2 & 0,1 & 1,2 & 0,1 & 1,8 & 0,1 & 1,3 & 0,1 & 0,7 & 0 & 0,7 & 0 & 0 & 0 & 0 & 0 & 0,8 & 0 & 0,93 & 0,04 \\
\hline $35-39$ & 3,7 & 0,2 & 1,8 & 0,1 & 2,2 & 0,1 & 1,7 & 0,1 & 3,3 & 0,2 & 1,6 & 0,1 & 1,7 & 0,1 & 2,3 & 0,1 & 0,6 & 0 & 1,8 & 0,1 & 2,07 & 0,11 \\
\hline $40-44$ & 2,2 & 0,1 & 2,2 & 0,1 & 1,3 & 0,1 & 4,5 & 0,3 & 3,8 & 0,2 & 4,2 & 0,3 & 2,3 & 0,1 & 2,3 & 0,1 & 1,6 & 0,1 & 4,4 & 0,3 & 2,88 & 0,17 \\
\hline $45-49$ & 5,2 & 0,3 & 3,9 & 0,2 & 6,6 & 0,4 & 3,3 & 0,2 & 13,2 & 0,8 & 6,6 & 0,4 & 3,5 & 0,2 & 10,1 & 0,6 & 5,8 & 0,4 & 11 & 0,7 & 6,92 & 0,42 \\
\hline $50-54$ & 9,6 & 0,5 & 4,4 & 0,2 & 10,7 & 0,5 & 6,1 & 0,3 & 4,5 & 0,2 & 17,2 & 0,9 & 14,2 & 0,7 & 13,8 & 0,7 & 10 & 0,5 & 14,2 & 0,7 & 10,5 & 0,52 \\
\hline $55-59$ & 16,8 & 0,7 & 14,5 & 0,6 & 18,1 & 0,7 & 10,9 & 0,4 & 17,9 & 0,7 & 17,1 & 0,7 & 21,1 & 0,8 & 15,3 & 0,6 & 25,1 & 1 & 25,1 & 1 & 18,2 & 0,72 \\
\hline $60-64$ & 20,4 & 0,8 & 19,6 & 0,8 & 36 & 1,4 & 30,1 & 1,2 & 23,1 & 0,9 & 32,8 & 1,3 & 17,3 & 0,7 & 18,4 & 0,7 & 25,1 & 1 & 22,9 & 0,9 & 24,6 & 0,97 \\
\hline $65-69$ & 26,1 & 0,8 & 51,2 & 1,5 & 43,1 & 1,3 & 39,1 & 1,2 & 51,2 & 1,5 & 34,7 & 1 & 29,2 & 0,9 & 29,4 & 0,9 & 39,3 & 1,2 & 35,6 & 1,1 & 37,9 & 1,14 \\
\hline $70-74$ & 60,5 & 1,2 & 55,2 & 1,1 & 47,3 & 0,9 & 60,9 & 1,2 & 49 & 1 & 60,2 & 1,2 & 40,5 & 0,8 & 36,9 & 0,7 & 48,1 & 1 & 53,6 & 1,1 & 51,2 & 1,02 \\
\hline $75-79$ & 63,5 & 0,6 & 65,5 & 0,7 & 65,7 & 0,7 & 65,7 & 0,7 & 51,4 & 0,5 & 47,6 & 0,5 & 40,7 & 0,4 & 58,7 & 0,6 & 48,6 & 0,5 & 58 & 0,6 & 56,5 & 0,58 \\
\hline $80-84$ & 26,3 & 0,1 & 28,7 & 0,1 & 49,1 & 0,2 & 31 & 0,2 & 41,8 & 0,2 & 23,8 & 0,1 & 44,5 & 0,2 & 44,4 & 0,2 & 45 & 0,2 & 41,5 & 0,2 & 37,6 & 0,17 \\
\hline$\geq 85$ & 15 & 0,1 & 18,4 & 0,1 & 6,8 & 0 & 17,1 & 0,1 & 19,9 & 0,1 & 16,3 & 0,1 & 22,6 & 0,1 & 19,4 & 0,1 & 33,6 & 0,2 & 13,4 & 0,1 & 18,3 & 0,1 \\
\hline$\geq 15$ & 11,1 & 7,1 & 12,3 & 7,5 & 15,3 & 8,5 & 14,4 & 7,9 & 13,6 & 8,3 & 13,1 & 8,4 & 10,7 & 6,9 & 11,1 & 7 & 12,5 & 7,9 & 13,5 & 8,6 & 12,8 & 7,81 \\
\hline $\begin{array}{l}\text { Все } \\
\text { население }\end{array}$ & 8,7 & 5,6 & 9,6 & 5,8 & 10,8 & 6,7 & 10,2 & 6,1 & 10,9 & 6,5 & 10,6 & 6,6 & 8,7 & 5,4 & 9,1 & 5,4 & 10,4 & 6,1 & 11,2 & 6,7 & 10 & 6,09 \\
\hline
\end{tabular}


Таблица 3

Тенденции первичной заболеваемости РЛ в возрастных группах взрослого населения РБ за 1993-2002 г2. в "грубых" (I) и стандартизованных (II) показателях

\begin{tabular}{|c|c|c|c|c|c|c|c|c|c|c|c|c|c|c|c|c|c|c|c|c|c|c|}
\hline \multirow[t]{2}{*}{$\begin{array}{l}\text { Возрастные } \\
\text { группы, лет }\end{array}$} & \multicolumn{2}{|c|}{1993} & \multicolumn{2}{|c|}{1994} & \multicolumn{2}{|c|}{1995} & \multicolumn{2}{|c|}{1996} & \multicolumn{2}{|c|}{1997} & \multicolumn{2}{|c|}{1998} & \multicolumn{2}{|c|}{1999} & \multicolumn{2}{|c|}{2000} & \multicolumn{2}{|c|}{2001} & \multicolumn{2}{|c|}{2002} & \multicolumn{2}{|c|}{$\begin{array}{l}\text { Усред- } \\
\text { ненные }\end{array}$} \\
\hline & I & II & I & II & I & II & I & II & I & II & I & II & I & II & I & II & I & II & I & II & I & II \\
\hline $15-19$ & 0,6 & 0,1 & 0,3 & 0 & 0,3 & 0 & 0,3 & 0 & 0 & 0 & 0 & 0 & 0,2 & 0 & 0,2 & 0 & 0 & 0 & 0 & 0 & 0,19 & 0,01 \\
\hline $20-24$ & 0 & 0 & 0,7 & 0,1 & 0,4 & 0 & 0 & 0 & 0 & 0 & 0,7 & 0,1 & 0 & 0 & 0,3 & 0 & 0,3 & 0 & 0 & 0 & 0,24 & 0,02 \\
\hline $25-29$ & 0,4 & 0 & 0,7 & 0,1 & 0,8 & 0,1 & 1,9 & 0,2 & 0,8 & 0,1 & 0 & 0 & 1,5 & 0,1 & 0,4 & 0 & 0,4 & 0 & 0,4 & 0 & 0,73 & 0,06 \\
\hline $30-34$ & 2,5 & 0,2 & 1,7 & 0,1 & 1,8 & 0,1 & 2,8 & 0,2 & 1,3 & 0,1 & 0,3 & 0 & 1,4 & 0,1 & 1,5 & 0,1 & 1,9 & 0,1 & 1,9 & 0,1 & 1,71 & 0,11 \\
\hline $35-39$ & 5,8 & 0,4 & 5,2 & 0,3 & 5,5 & 0,3 & 3 & 0,2 & 4,3 & 0,3 & 5,2 & 0,3 & 4,7 & 0,3 & 4,1 & 0,2 & 2,2 & 0,1 & 4,3 & 0,3 & 4,43 & 0,27 \\
\hline $40-44$ & 13,8 & 0,8 & 17,5 & 1 & 12,8 & 0,8 & 14,1 & 0,8 & 15,3 & 0,9 & 10,4 & 0,6 & 8,5 & 0,5 & 12,5 & 0,8 & 9,7 & 0,6 & 11,1 & 0,7 & 12,6 & 0,75 \\
\hline $45-49$ & 27,3 & 1,6 & 45 & 2,7 & 33 & 2 & 33 & 2 & 40,5 & 2,4 & 31,7 & 1,9 & 32,5 & 2 & 32,7 & 2 & 33,2 & 2 & 28,5 & 1,7 & 33,7 & 2,03 \\
\hline $50-5$ & 71 & 3,5 & 53,8 & 2,7 & 65,3 & 3,3 & 5 & 2,8 & 4 & 3,6 & 2 & 3,2 & 62,4 & 3,1 & 9,1 & 3 & 6 & 3,2 & 70 & 3,5 & 63,7 & 3,19 \\
\hline $55-59$ & 118 & 4,7 & 64,2 & 2,6 & 111 & 4,4 & 94,8 & 3,8 & 101 & 4 & 98,5 & 3,9 & 105 & 4,2 & 111 & 4,4 & 99,3 & 4 & 103 & 4,1 & 101 & 4,01 \\
\hline $60-64$ & 150 & 6 & 141 & 5,6 & 158 & 6,3 & 164 & 6,6 & 144 & 5,8 & 149 & 6 & 136 & 5,4 & 137 & 5,5 & 137 & 5,5 & 121 & 4,8 & 144 & 5,75 \\
\hline $65-69$ & 188 & 5,6 & 228 & 6,8 & 194 & 5,8 & 178 & 5,3 & 195 & 5,9 & 178 & 5,3 & 160 & 4,8 & 169 & 5,1 & 172 & 5,2 & 167 & 5 & 183 & 5,48 \\
\hline $70-74$ & 169 & 3,4 & 176 & 3,5 & 140 & 2,8 & 174 & 3,5 & 185 & 3,7 & 191 & 3,8 & 165 & 3,3 & 164 & 3,3 & 192 & 3,8 & 181 & 3,6 & 174 & 3,47 \\
\hline $75-79$ & 167 & 1,7 & 153 & 1,5 & 166 & 1,7 & 115 & 1,2 & 162 & 1,6 & 136 & 1,4 & 122 & 1,2 & 158 & 1,6 & 151 & 1,5 & 178 & 1,8 & 151 & 1,52 \\
\hline $80-84$ & 43,8 & 0,2 & 51,5 & 0,3 & 101 & 0,5 & 72,2 & 0,4 & 72,9 & 0,4 & 75,3 & 0,4 & 94,9 & 0,5 & 71,6 & 0,4 & 88,4 & 0,4 & 110 & 0,5 & 78,2 & 0,4 \\
\hline$\geq 85$ & 28 & 0,1 & 34 & 0,2 & 28,5 & 0,1 & 48,5 & 0,2 & 52,7 & 0,3 & 32,6 & 0,2 & 42,7 & 0,2 & 45,4 & 0,2 & 60,9 & 0,3 & 47,1 & 0,2 & 42 & 0,2 \\
\hline$\geq 15$ & 48,4 & 36,3 & 49,2 & 35,3 & 55 & 36,2 & 52,5 & 34,7 & 49,2 & 37 & 46,6 & 34,7 & 43,6 & 33 & 44,7 & 34 & 45,8 & 34,4 & 45,1 & 33,8 & 48 & 34,9 \\
\hline $\begin{array}{l}\text { Все } \\
\text { население }\end{array}$ & 37,1 & 28,3 & 37,7 & 27,5 & 37,7 & 28,3 & 36 & 21 & 38,6 & 28,9 & 36,9 & 27,1 & 34,9 & 25,7 & 36,1 & 26,5 & 37,5 & 26,8 & 36,9 & 26,4 & 36,9 & 27,3 \\
\hline
\end{tabular}

показатель заболеваемости у мужчин был отмечен в возрастной группе 70-74 года (433,0 на 100 тыс. населения), стандартизованный - в группах 65-69 и 60-64 лет (12,3 на 100 тыс. и 12,2 на 100 тыс. населения). Усредненный "грубый" показатель заболеваемости новообразованиями трахеи, бронхов, легкого среди женского населения РБ старше 15 лет за 1993-2002 гг. составлял 12,8 на 100 тыс. населения, стандартизованный - 7,81 на 100 тыс. населения. Соотношение усредненных "грубых" показателей заболеваемости женского населения РБ старше 15 лет и всего женского населения составило 1,4. Максимальным усредненный "грубый" показатель заболеваемости женского населения РБ был в группе 75-79 лет (56,58 на 100 тыс. населения), стандартизованный - в группе 65-69 лет (1,148 на 100 тыс. населения).

При сравнении половозрастных показателей заболеваемости РЛ с имеющимися эпидемиологическими данными по Санкт-Петербургу [3], можно отметить, что максимальные показатели заболеваемости как у мужчин, так и у женщин наблюдаются в те же возрастные интервалы, что и по РБ. В СанктПетербурге наибольшие показатели заболеваемости были отмечены среди мужчин в возрасте 70 лет (521,1 на 100 тыс. населения), а у женщин в возрасте $\geq 80$ лет (86,0 на 100 тыс. населения).

В сравнении с общероссийскими показателями за аналогичный период стандартизованные показатели заболеваемости РЛ среди мужского и женского населения РБ по своему уровню близки к среднероссийским [2].

Соотношение повозрастных усредненных показателей заболеваемости новообразованиями трахеи, бронхов, легкого одновозрастных групп мужского и женского населения РБ старше 15 лет нарастало прямо пропорционально возрасту. Минимальным оно было в группах от 15-19 $(2,7)$ и до 35-39 лет $(3,3)$, далее нарастало от 7,8 (в группе 40-44 года) до максимума 12,4 (в группе 60-64 года), а далее имело тенденцию к снижению до 8,7 в группе $\geq 85$ лет (табл. 4).

Данные табл. 4 убедительно демонстрируют тот факт, что мужчины заболевают РЛ чаще, чем женщины, во всех возрастных интервалах наблюдения, по

Таблица 4 Соотношение усредненных повозрастных показателей заболеваемости основными формами злокачественных новообразований в возрастных группах взрослого мужского и женского населения РБ в 1993-2002 г2.

\begin{tabular}{|l|c|c|c|c|}
\hline \multirow{2}{*}{$\begin{array}{c}\text { Возрастные } \\
\text { группы, лет }\end{array}$} & \multicolumn{4}{|c}{ Локализация } \\
\cline { 2 - 5 } & желудок & $\begin{array}{c}\text { ободочная } \\
\text { кишка }\end{array}$ & $\begin{array}{c}\text { прямая } \\
\text { кишка }\end{array}$ & $\begin{array}{c}\text { трахея, } \\
\text { бронхи, легкое }\end{array}$ \\
\hline $15-19$ & - & 0,7 & - & 2,7 \\
\hline $20-24$ & 1,1 & 0,5 & 1,7 & 1,3 \\
$25-29$ & 1,2 & 0,9 & 0,9 & 1,1 \\
\hline $30-34$ & 0,8 & 0,9 & 1,8 & 2,7 \\
\hline $35-39$ & 1,7 & 0,6 & 0,7 & 3,3 \\
\hline $40-44$ & 1,8 & 1 & 0,9 & 7,8 \\
\hline $45-49$ & 2,3 & 1 & 0,9 & 9 \\
\hline $50-54$ & 3 & 1 & 1,3 & 12 \\
\hline $55-59$ & 3 & 1,2 & 1,3 & 11,3 \\
\hline $60-64$ & 2,7 & 1,2 & 1,7 & 12,4 \\
\hline $65-69$ & 2,4 & 1,4 & 1,9 & 10,8 \\
\hline $70-74$ & 2,5 & 1,5 & 1,9 & 8,5 \\
\hline $75-79$ & 2,3 & 1,6 & 2,2 & 7,6 \\
\hline $80-84$ & 2,6 & 2,2 & 2,7 & 6,1 \\
\hline$\geq 85$ лет & 3,4 & 1,8 & 3,6 & 8,7 \\
\hline 15 & 1,7 & 0,9 & 1,2 & 7 \\
\hline Все & & & & \\
население & 1,7 & 0,9 & 1,1 & 6,7 \\
\hline
\end{tabular}




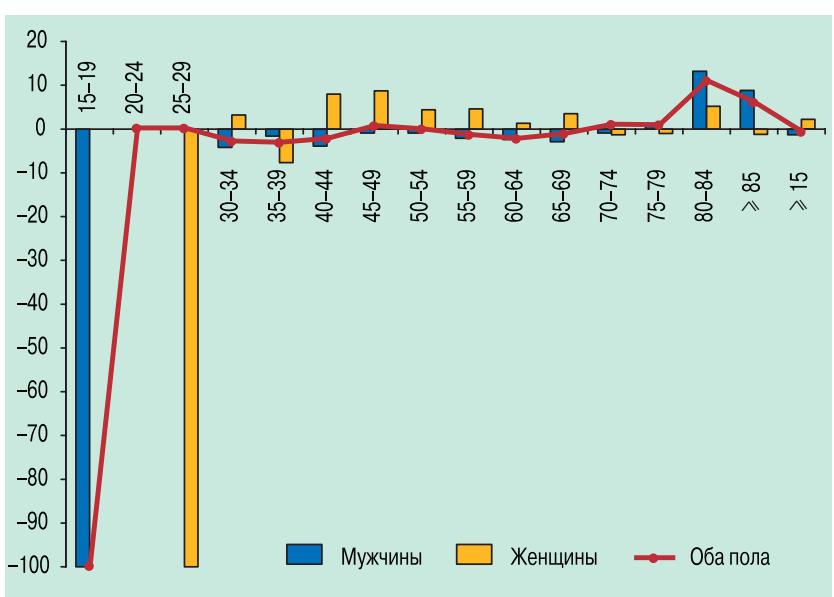

Рисунок. Среднегодовой темп прироста и убыли "грубых" показателей заболеваемости новообразованиями трахеи, бронхов, легкого по возрастным группам взрослого населения РБ в 1993-2002 гг.

сравнению с другими распространенными локализациями рака, за исключением рака желудка.

Начиная с 1990 г. в РФ регистируется снижение заболеваемости РЛ среди мужского населения. В РБ также отмечена убыль "грубого" показателя заболеваемости новообразованиями трахеи, бронхов, легкого мужского населения старше 15 лет, которая за период 1993-2002 гг. составила в среднем 1,3\% в год (рисунок).

\section{Заключение}

В результате наших исследований было выявлено, что заболеваемость женщин старше 15 лет новообразованиями этой нозологической группы имела тенденцию к росту: за период с 1993 по 2002 г. показатель прирастал в среднем на 2,2 \% в год, в популяции всего населения РБ старше 15 лет за последние 10 лет наблюдается отрицательный темп прироста, заболеваемость убывала со средней скоростью 0,8 \% в год.

Из многочисленных эпидемиологических исследований известно, что курение является причиной $90 \%$ всех случаев рака легкого среди мужчин. На основании нашего исследования можно заключить, что заболеваемость РЛ среди женщин в РБ еще не велика, ввиду того, что женщины в своей массе начали курить значительно позже, чем мужчины, а реализации эффекта канцерогенного воздействия требуется 20-25-летний латентный период. Однако рост процента курящих женщин приведет к росту заболеваемости РЛ, тенденция которого выявлена в нашем исследовании.

Таким образом, РЛ за исследованный период характеризуется высокими показателями заболеваемости, при тенденции к их снижению среди мужского населения и нарастанию среди женского населения РБ.

\section{Литература}

1. Давыдов М.И., Демидов Л., Поляков Б. Современное состояние и проблемы онкологии. Врач 2006; 13: 3-7.

2. Давыдов М.И., Аксель Е.М. Заболеваемость злокачественными новообразованиями и смертность от них в странах СНГ в 2005 г. Вестник РАМН 2007; 11: 45-49.

3. Мерабишвили В.М., Дятченко О.Т. Статистика рака легкого (заболеваемость, смертность, выживаемость). Практ. онкол. 2000; 3: 3-7.

4. Тюляндин С.А., Моисеенко В.М. (ред.). Практическая онкология: Избранные лекции. СПб.: Центр ТОММ; 2004.

5. Чиссов В.И., Дарьялова. С.Л. (ред.) Избранные лекции по клинической онкологии. М.; 2000.

\section{Информация об авторах}

Ганцева Халида Ханафиевна - д. м. Н., проф., зав. кафедрой внутренних болезней ГОУ ВПО "Башкирский государственный медицинский университет Росздрава": тел.: (347) 272-56-25, тел. / факс: (347) 272-41-73; e-mail: umu@inbox.ru

Рахматуллина Ирина Робинзоновна - д. М. н., проф. кафедры хирургии и онкологии ГОУ ВПО "Башкирский государственный медицинский университет Росздрава"; тел.: (347) 272-56-25, тел. / факс: (347) 272-41-73; e-mail: umu@inbox.ru

Габитова Дильбар Марсельевна - к. м. н., доцент кафедры внутренних болезней ГОУ ВПО "Башкирский государственный медицинский университет Росздрава"; тел.: (347) 272-56-25, тел.: / факс: (347) 272-41-73; e-mail: Dilbar.Gabitova@ mail.ru

Поступила 09.02.10 (С) Коллектив авторов, 2010 удК 616.24-006.6:313(470.21) 